\title{
Functional Role of Second Heart Field-derived Cells in Aortic Integrity in Mice
}

Hisashi Sawada ${ }^{1,2,3}$, Hideyuki Higashi ${ }^{4}$, Chen Zhang ${ }^{5,6}$, Yanming $\mathrm{Li}^{5,6}$, Yuriko Katsumata ${ }^{7,8}$, Stephanie Morgan ${ }^{4}$, Lang H. Lee ${ }^{4}$, Sasha A. Singh ${ }^{4}$, Jeff Z. Chen $^{1,3}$, Michael K. Franklin ${ }^{1}$, Jessica J. Moorleghen ${ }^{1}$, Deborah A. Howatt ${ }^{1}$, Debra L. Rateri ${ }^{1}$, Hong S. Lu ${ }^{1,2,3}$, Ying H. Shen ${ }^{5,6}$, Scott A. LeMaire ${ }^{5,6}$, Masanori Aikawa ${ }^{4}$, Mark W. Majesky ${ }^{9}$, Alan Daugherty ${ }^{1,2,3}$

1. Saha Cardiovascular Research Center, College of Medicine, University of Kentucky, KY

2. Saha Aortic Center, College of Medicine, University of Kentucky, KY

3. Department of Physiology, College of Medicine, University of Kentucky, KY

4. Center for Interdisciplinary Cardiovascular Sciences, Cardiovascular Division, Department of Medicine, Brigham and Women's Hospital, Harvard Medical School, Boston, MA

5. Division of Cardiothoracic Surgery, Michael E. DeBakey Department of Surgery, Baylor College of Medicine, Houston, TX

6. Department of Cardiovascular Surgery, Texas Heart Institute, Houston, TX

7. Department of Biostatistics, University of Kentucky, KY

8. Sanders-Brown Center on Aging, University of Kentucky, KY

9. Center for Developmental Biology \& Regenerative Medicine, Seattle Children's Research Institute, Departments of Pediatrics and Pathology, University of Washington, Seattle, WA

Running title: SHF-derived cells impact aortic integrity

\author{
Corresponding author: \\ Alan Daugherty \\ Saha Cardiovascular Research Center, University of Kentucky \\ 741 South Limestone Street \\ BBSRB, B243 \\ Lexington, KY, 40536, USA. \\ Tel: +1-859-323-3512 \\ E-mail: alan.daugherty@uky.edu
}

\section{Word count:}

Abstract: 338 words

Manuscript: 4,484 words 


\section{Abstract}

Background: The ascending aorta is a common location for thoracic aortopathies. Pathology predominates in the aortic media with disease severity being most apparent in outer laminar layers of the ascending aorta. Smooth muscle cells (SMCs) and selected fibroblasts in these regions are derived from second heart field (SHF). SHFderived cells have a distinct distribution, and the localization of SHF coincides with the regional specificity in some forms of thoracic aortopathies. However, the role of SHFderived cells in maintaining the structural and functional integrity of the ascending aorta remains unclear.

Methods: Mass spectrometry assisted proteomic and single cell transcriptomic analyses were performed in angiotensin (Angll)-infused mouse aortas to investigate the molecular mechanism of the regional specificity of thoracic aortopathies and discriminate molecular features of SHF-derived cells in maintaining the aortic homeostasis. Genetic deletion of either transforming growth factor- $\beta$ receptor 2 (Tgfbr2) or low-density lipoprotein receptor-related protein 1 (Lrp1) in SHF-derived cells was conducted to examine the impact of SHF-derived cells on the integrity of aortic wall.

Results: Proteomic analysis identified the alteration of protein profiles by Angll infusion in a region-specific manner. Angll evoked differential expression of multiple proteins related to extracellular matrix organization. Histological analysis demonstrated that Angll-induced medial disruptions were predominantly in the outer laminar layers derived from the SHF. Single cell transcriptomic analysis revealed that elastin, a major component of extracellular matrix, was less abundant in SHF-derived SMCs and fibroblasts compared to those from other origins. In addition, mRNA of Tgfbr2 and Lrp1, key molecules for extracellular maturation, were abundant in SHF-derived SMCs of control aortas. Angll infusion decreased $L r p 1$ mRNA abundance. To examine biological effects of SHF-derived cells, either TGFBR2 or LRP1 were deleted in SHF-derived cells in mice. SHF-specific TGFBR2 deletion led to embryonic lethality at E12.5 with dilatation of the outflow tract and retroperitoneal hemorrhage in mice. LRP1 deletion in SHF-derived cells augmented Angll-induced aortic aneurysm and rupture in the ascending region.

Conclusion: These results demonstrate that SHF-derived cells exert a critical role in maintaining the integrity of the ascending aorta in mice. 


\section{Introduction}

Thoracic aortopathies are a spectrum of lethal diseases associated with aneurysms, dissection, and rupture. ${ }^{1,2}$ Despite the devastating consequences of these diseases, current medical therapy has limited efficacy. Therefore, there is an urgent need to investigate mechanisms of thoracic aortopathies to facilitate development of novel therapeutics.

Aortopathies occur throughout the thoracic aorta with the ascending aortic segment being a frequently affected region. ${ }^{3,4}$ Aortic remodeling including medial and adventitial thickenings is a histological feature of thoracic aortopathies, and this pathology shows a gradient across the media that is detected predominantly in outer laminar layers. ${ }^{5-10}$ Therefore, thoracic aortopathies have regional and transmural specificities with outer medial layers in the ascending aorta being a disease-prone location. However, the mechanism by which outer medial layers of the ascending aorta are prone to aortopathy remains unclear.

The major cellular component of the aortic wall is smooth muscle cells (SMCs) and fibroblasts. These cells exert a pivotal role in the pathogenesis of thoracic aortopathies. ${ }^{11}$ SMCs in the ascending aorta are derived from two different embryonic origins: cardiac neural crest (CNC) and second heart field (SHF). ${ }^{12}$ Selected fibroblasts are derived from the CNC and SHF. ${ }^{13}$ Although it is not possible to grossly discern the origin of these cells, lineage tracking studies have demonstrated that CNC-and SHFderived SMCs occupy inner and outer medial layers, respectively, of the ascending aorta. ${ }^{13}$ The region-specific distribution of thoracic aortopathies appears to coincide with distribution of SMCs from the SHF rather than CNC. Thus, differences of embryonic origins may lead to functional differences that have pathological consequences. However, there is scant evidence supporting this hypothesis. In this study, we investigated whether SHF-derived cells colocalized with the evolution of aortic pathology produced by chronic angiotensin II (AnglI) infusion in mice, ${ }^{6,14,15}$ and investigated the molecular basis for the regional specificity of thoracic aortopathies using proteomic and single cell transcriptomic approaches. The omics studies identified transforming growth factor (TGF)- $\beta$ receptor 2 (TGFBR2) and low-density lipoprotein receptor-related protein 1 (LRP1) as potential targets. SHF-specific deletion of either Tgfbr2 or Lrp1 gene was then performed to investigate the effects of SHF-derived cells on the integrity of aortic wall. 


\section{Methods}

Additional detailed methods are presented in Supplemental Methods. Numerical data are available in Supplemental Excel File I. All raw data and analytical methods are available from the corresponding author upon appropriate request.

Mice

The following mice were purchased from The Jackson Laboratory (Supplemental Table I): ROSA26R ${ }^{\text {LacZ }}$ (\#003474), ROSA26R ${ }^{m T / m G}$ (\#007676), Lrp1 floxed (\#012604), Tgfbr2 floxed (\#012603), and Wnt1-Cre [\#022501 (C57BL/6J background, also known as B6-Wnt1-Cre2), \#022137 (Wnt1-Cre2 on a 129S4 background)]. Mef2c-Cre mice (\#030262) were purchased from the Mutant Mouse Resource and Research Center. For cell tracking studies of CNC and SHF origins, either B6-Wnt1-Cre2 or Mef2c-Cre male mice were bred to ROSA26R ${ }^{\mathrm{LacZ}}$ female mice, respectively. For the single cell RNA sequence study, Mef2c-Cre male mice were bred to ROSA26R ${ }^{m T / m G}$ female mice. To delete Lrp1 in CNC-derived cells, Lrp1 floxed female mice were bred with either B6Wnt1-Cre2 or Wnt1-Cre2 (129S4 background) mice. Embryonic lethality, a phenotype of Lrp1 deletion in CNC-derived cells, was examined in both Wnt1-Cre2 strains. Embryos with CNC-specific LRP1-deletion were harvested from Lrp1 floxed female mice bred with Wnt1-Cre2 (129S4 background) males to investigate the cause of death. Mef2cCre male mice were crossbred to Lrp 1 floxed female to delete $L r p 1$ in SHF-derived cells. Wnt1-Cre and Mef2c-Cre male mice were used for lineage-specific deletion of Tgfbr2 in CNC and SHF-derived cells, respectively. Because of the low incidence of Angll-induced thoracic aortic aneurysms (TAAs) in female mice, only male mice were studied. ${ }^{16}$ All experiments were approved by the IACUC at either the University of Kentucky or Baylor College of Medicine in accordance with the guidelines of the National Institutes of Health.

\section{Pump implantation}

After random assignment, either saline or Angll $(1,000 \mathrm{ng} / \mathrm{kg} / \mathrm{min}, \mathrm{H}-1705$, Bachem) was infused via a subcutaneously implanted osmotic pump (either Alzet model 2001 for 3 days for experiments using aortic tissues prior to overt pathology, or model 2004 for 28 days, Durect) into male mice at 10 to 14 weeks of age, as described previously. ${ }^{17}$ Surgical staples were used to close incision sites and were removed 7 days after surgery. Post-operative pain was alleviated by application of topical lidocaine cream (4\% wt/wt, LMX4, \#0496-0882-15, Eloquest Healthcare, Inc).

\section{Aortic tissue proteolysis for mass spectrometry assisted proteomics}

Aortic tissues, harvested after 3 days of either saline or Angll infusion, were minced before submersion in RIPA buffer (\#9806, Cell Signaling Technology) supplemented with protease inhibitor cocktail (\#P8340, Sigma-Aldrich). Tissue pieces were placed in a Precellys CK14 homogenizing tube with RIPA buffer and ceramic beads (1.4 mm; Bertin Instruments). Samples were homogenized using a Precellys 24 tissue homogenizer using three 10 second cycles at 5,000 rpm. Debris were removed by centrifugation for 10 minutes at $4{ }^{\circ} \mathrm{C}$ and protein concentrations of supernatant samples were measured using the Pierce BCA Protein Assay (\#23225, Thermo Fisher). Equal amounts of protein $(10 \mu \mathrm{g})$ for each aortic segment were processed using the 
PreOmics iST in solution trypsinization kit (\#00027, PreOmics) according to the manufacturer's recommended protocols. The final peptide precipitate was dissolved in sample buffer ( $40 \mu \mathrm{l}, 5 \% \mathrm{wt} / \mathrm{vol}$ acetonitrile, $0.5 \% \mathrm{wt} / \mathrm{vol}$ formic acid in mass spectrometry grade water).

\section{Human aortic samples}

Ascending aortas were acquired from patients undergoing aortic surgery for sporadic thoracic aortic aneurysms at Baylor College of Medicine $(n=10,5$ males and 5 females, age $=66 \pm 7$ years, aortic diameters $=5.3 \pm 0.4 \mathrm{~cm}$ ). Aortic tissues were fixed with formalin (10\% wt/vol) and then incubated with ethanol $(70 \% \mathrm{vol} / \mathrm{vol})$, as described previously. ${ }^{18}$ Subsequently, tissues were embedded in paraffin blocks, and sliced into 5 $\mu \mathrm{m}$ sections.

\section{Aortic cell suspension for single cell RNA sequencing (scRNAseq)}

Ascending aortic samples were harvested from Mef2c-Cre ROSA26R ${ }^{\mathrm{mT} / \mathrm{mG}}$ male mice $(n=5)$ at baseline and after 3 days of Angll infusion $(1,000 \mathrm{ng} / \mathrm{kg} / \mathrm{min}, \mathrm{H}-1705$, Bachem). Aortic samples were pooled in Hanks' Balanced Salt Solution (HBSS, \#14175095, Thermo Fisher Scientific) with fetal bovine serum (10\% vol/vol). Periaortic tissues were removed and aortic tissues were cut into small pieces. Aortic samples were subsequently digested with enzyme cocktail (Supplemental Table II) in Ca/Mg contained-HBSS (\#14025092, Thermo Fisher Scientific) for 60 minutes at $37^{\circ} \mathrm{C}$. Cell suspensions were filtered through a $40 \mu \mathrm{m}$ cell strainer (CLS431750-50EA, SigmaAldrich), centrifuged at $300 \mathrm{~g}$ for 10 minutes, and resuspended using cold HBSS (\#14175095) with fetal bovine serum (5\% vol/vol). Cells were stained with DAPI and sorted to select viable cells ( $\geq 95 \%$ viability) by flow cytometry (FACS Aria III, BD Biosciences). Cells were also sorted based on mTomato and mGFP signals.

\section{Statistical analyses}

Data are presented as the mean \pm standard error of the mean. Normality and homogeneity of variance were assessed by Shapiro-Wilk and Brown-Forsythe tests, respectively. Because the original data of ascending aortic diameter and Western blot for Serpine1 did not pass Shapiro-Wilk or Brown-Forsythe test, $\log _{10}$ or square root transformation was applied to pass these tests, respectively. After confirming homogeneous variances and normality, two-group or multi-group comparisons for means were performed by two-sided Student's t-test or two-way analysis of variance (ANOVA) with Holm-Sidak multiple comparison test, respectively. Since data of a-SMA abundance and collagen deposition in human TAAs did not pass Shapiro-Wilk or Brown-Forsythe test even after transformation, Mann-Whitney $U$ test was applied for these data. The log-rank test was used to compare the probabilities of ascending aortic rupture between groups. In the log-rank test, deaths due to other causes such as abdominal aortic rupture were censored. $\mathrm{P}<0.05$ was considered statistically significant. Statistical analyses mentioned above were performed using SigmaPlot version 14.0 (SYSTAT Software Inc.).

Statistical analyses for proteomics data were performed by Qlucore Omics Explorer 3.5 (Qlucore). For a principal component analysis (PCA) plot and heat maps, proteins were filtered by their false discovery rate adjusted $P$ value ( $Q$-value) of multiple 
group comparisons with $\mathrm{Q}=0.1$ as a threshold. Proteins in the principal component analysis (PCA) plot were clustered by $k$-means algorithm $(k=3)$. Protein-protein interaction networks were examined using the STRING database (version 11.0) in Cytoscape (version 3.8.0).$^{19}$ Interactions were acquired using the following thresholds: confidence interaction scores $\geq 0.7$, active interaction sources=text mining, experiments, databases, co-expression, neighborhood, gene fusion, co-occurrence. Enrichment analyses were performed using the Enrichr webtool. ${ }^{20}$

scRNAseq data analyses were performed using the Seurat package (version 3.9.9.9038) on R (version 3.6.2). ${ }^{21}$ Four mapped unique molecular identifier (UMI) counts datasets from mTomato and mGFP positive cells (baseline-SHF, baseline-nSHF, Angll-SHF, and Angll-nSHF) were imported into R separately. Seurat objects for each of the UMI count datasets were built using the "CreateSeuratObject" function by the following criteria: $\geq 3$ cells and $\geq 200$ detected genes. Cells expressing less than 200 or more than 5,000 genes were filtered out for exclusion of non-cell or cell aggregates, respectively. Cells with more than $10 \%$ mitochondrial genes were also excluded. UMI counts were then normalized as the following: counts for each cell were divided by total counts, multiplied by 10,000 , and transformed to natural-log. "FindlntegrationAnchors" and "IntegrateData" functions were used to remove batch effects and integrate the four normalized datasets. Uniform manifold approximation and projection (UMAP) dimensionality reduction to 20 dimensions for the first 30 principal components (PCs) was applied to identify cell clusters using the normalized- and scaled-UMI count data. "FindAllMarkers" and "FindConcervedMarkers" functions were used to identify conserved marker genes to determine cell types of each of the clusters. Differentially expressed genes were examined using a zero-inflated negative binomial regression model with two factors (embryonic origin and infusion) and their interaction from "zinbwave" and "edgeR" $R$ packages. ${ }^{22,23} \mathrm{Q}$ value $<0.05$ was used as a threshold to identify differentially expressed genes. 


\section{Results}

Region-specific alteration of aortic protein profiles following Angll infusion

Angll was infused into C57BL/6J mice, and ascending and descending aortic tissues were harvested after 3 days prior to development of overt pathology. Aortas from saline-infused mice were included as controls. Mass spectrometry-assisted proteomics was performed to investigate mechanisms driving regional specificity of TAAs. Proteomic analysis identified 2,644 proteins among all aortic samples. In PCA using the unfiltered proteome, protein profiles were not significantly different between ascending and descending aortas in saline-infused mice (Figure 1A). However, Angll infusion altered these profiles compared to saline infusion, and profiles were significantly different between ascending and descending thoracic regions $(40 \%$ variation along PC1, Figure 1A). Compared to the saline-infused group, Angll infusion differentially regulated 864 and 1189 protein abundances in the ascending and descending aortas, respectively (Figure 1B, C). Within Angll-infused mice, abundances of 77 proteins were different between ascending and descending aortas (Figure 1D, Supplemental Excel File II). Forty-one proteins were common among these three subsets (Figure 1E). Thus, these 41 molecules were altered during Angll infusion in a region-specific manner, suggesting their contribution to mechanisms of TAAs. To gather insight into the characteristics of the 41 proteins, enrichment analysis in biological process was performed. Fifteen and 26 proteins were down and upregulated, respectively, in the ascending aorta of Angll-infused mice (Figure 1F). Although there was no significant annotation in 15 downregulated proteins, multiple terms were annotated in 26 upregulated proteins (Figure 1G). Extracellular matrix (ECM) organization was the top annotation including Serpine1, thrombospondin1 (Thbs1), and Cd44 (Figure 1H). Western blot analyses verified the increase of these molecules during Angll infusion in a region-specific manner (Figure 1I). Protein-protein interaction analysis was also performed for the 41 overlapped proteins. Twenty-three proteins had interactions and there were two major clusters (Supplemental Figure I). One cluster was related to ribosome function and another cluster had an interaction with LRP1 as ligands. LRP1, a multi-functional protein expressed in SMCs, contributed to aortic wall integrity, with deletion of LRP1 in pan SMCs leading to TAA formation in mice. ${ }^{19,24-27}$ Because of high abundances in the descending aorta, these LRP1 ligands may play protective roles in the pathophysiology of Angll-induced TAAs.

Susceptibility of SHF-derived cells to Angll-induced medial and adventitial pathologies

We next examined interactions between SMC origins and Angll-induced aortic pathology. CNC- and SHF-derived cells were tracked using Wnt1- or Mef2c-Cre ROSA26R ${ }^{\text {LacZ }}$ mice infused with Angll. Consistent with our previous study, ${ }^{13}$ the ascending aorta was composed of both CNC- and SHF-derived SMCs with neither extending beyond the distal boundaries of the aortic arch (Figure 2A). Angll increased medial area, while it did not alter distribution of SMC origins (Figure 2B, C). Of interest, $\mathrm{X}$-gal positive areas were increased significantly in SHF-, but not CNC-, derived cells (Figure 2D). Because some adventitial fibroblasts are derived from the SHF, ${ }^{13}$ we also evaluated effects of Angll infusion on cells in the adventitia. Similar to the media, adventitial area was increased by Angll infusion (Figure 2B, Supplemental Figure IIA), and increased X-gal positive areas were observed only in SHF-derived cells 
(Supplemental Figure IIB). These data support that SHF-derived cells are susceptible to Angll-induced medial and adventitial thickenings.

Medial gradients of aortic pathologies in human thoracic aortic aneurysms

We next examined the presence of medial gradients in human sporadic TAAs. Immunostaining for $\alpha$-smooth muscle actin and Movat's pentachrome staining were performed to evaluate SMCs and ECM, respectively. Immunostaining for a-smooth muscle actin revealed that the outer media had significantly lower positive areas for asmooth muscle actin than the inner media in human TAA tissues (Figure 3A). Movat's pentachrome staining identified severe collagen deposition in the outer media (Figure 3B). Thus, consistent with mouse studies, human TAAs also have a transmural gradient of aortic pathologies.

Differential gene expression between SHF- and CNC-derived SMCs and fibroblasts

To investigate cell-specific differences between SHF- and CNC-derived cells, scRNAseq was performed using Mef2c-Cre ROSA26R ${ }^{m T / m G}$ male mice at baseline and after 3 days of Angll infusion. Aortic samples were harvested from the ascending region and suspended aortic cells were sorted by FACS based on mTomato and mGFP signals (Supplemental Figure IIIA). Since mGFP protein was present on Mef2c-Cre expressing cells of this mouse strain, mGFP positive cells were derived from the SHF, while mTomato positive cells were derived from the other origins (nSHF), including the CNC (Figure 4A). After sorting, scRNAseq was performed using mTomato and mGFP positive cells isolated at baseline or after Angll infusion. After removing batch effects, the four normalized datasets were properly integrated (Figure 4B, C). scRNAseq detected mRNA abundance in multiple cell types (Figure 4C, D, Supplemental Figure IIIB, C). In the SMC cluster, SHF-derived cells were composed of $41 \%$ SMCs (Figure 4D). There were 2,295 and 2,490 differentially expressed genes between origins at baseline and after Angll infusion, respectively (Figure 4E, Supplemental Figure IIID, Supplemental Excel File III). It is noteworthy that, except for one gene (Atn1, atrophin1) at baseline, all genes were common between origins at baseline and after Angll infusion (Supplemental Figure IIID). mRNAs related to SMC contractile proteins, such as Tagln, Myh11, and Cnn1, were more abundant in SHF-derived SMCs than in nSHF-derived SMCs at baseline (Figure 4F). Tagln and Cnn1 mRNA were increased consistently in Angll-infused SMCs of SHF origin (Figure 4F). Several collagen genes including collagen type 1a1, 1a2, 3a1, and 5a2 were abundant differentially between SMC origins at baseline and after Angll infusion (Figure 4G). Elastin, a major component of the aortic media, was significantly less abundant in SHF-derived SMCs compared to nSHF-derived SMCs (Figure 4G). In addition, Angll infusion further reduced the lesser abundance of elastin mRNA in SHF-derived SMCs ( $P=0.037$ by twoway ANOVA, Figure 4G, Supplemental Excel File III). We also evaluated mRNA related to ECM organization that were detected in the proteomic analysis. Serpine1 and Fn1 mRNA were less abundant in SHF-derived cells with Angll infusion (Supplemental Figure IIIE). Because the TGF- $\beta$ signaling pathway plays a pivotal role in ECM maturation, mRNA abundances of TGF- $\beta$ ligands and receptors were also examined. Tgfb2 and 3, TGF- $\beta$ ligands, were upregulated in SHF-derived SMCs compared to nSHF-derived SMCs at both baseline and after Angll infusion (Figure 4G). TGF- $\beta$ 
receptor 2 (Tgfbr2) mRNA was also highly abundant in SHF-derived SMCs regardless of infusion. Lrp1 (also known as Tgfbr5) mRNA was higher in SHF-derived SMCs at baseline, while it was not significantly different after Angll infusion (Figure 4G).

The transcriptome of adventitial fibroblasts in the ascending aorta was also examined (Supplemental Excel File IV). Tgfbr2 and Lrp1 mRNA abundances were higher in SHF-derived fibroblasts than in cells derived from other origins (Supplemental Figure IIIF). Despite the variation of collagen genes and TGF- $\beta$ ligands, elastin mRNA was less abundant in SHF-derived fibroblasts than in nSHF-derived fibroblasts at baseline and after Angll infusion (Supplemental Figure IIIF). Two major aortic cell types, SMCs and fibroblasts, had the same pattern of lower abundance of elastin mRNA in SHF-derived cells, indicating that lower elastin mRNA abundance in SHF-derived cells contributes to the susceptibility of these cells to aortic pathologies.

Prenatal thoracic aortopathy induced by TGF- $\beta$ receptor 2 deletion in SHF-derived cells Genetic mutations of TGFBR2 cause Loeys-Dietz syndrome with probands predisposed to aneurysms in humans. ${ }^{28-30}$ In mice, postnatal deletion of TGFBR2 in pan SMCs promotes severe TAA formation with pathologies localized to outer medial layers of the ascending aorta. ${ }^{9,31}$ Since regional and transmural location of aortic pathologies in Loeys-Dietz syndrome correspond to the distribution of SHF-derived cells, we investigated whether SHF-specific TGFBR2 deletion lead to aortic pathologies. SHFspecific TGFBR2 deletion led to embryonic lethality with retroperitoneal hemorrhage beginning at E12.5 (Figure 5A). In addition, the outflow tract was dilated significantly in fetuses with SHF-specific TGFBR2 deletion compared to wild type littermates (Figure 5A, B). Thus, TGFBR2 deficiency in SHF-derived cells led to prenatal thoracic aortopathies.

Augmentation of thoracic aortopathies by LRP1 deletion in SHF-derived cells

Deletion of LRP1 in all SMCs causes multiple aortic pathologies including aneurysm and tortuosity, ${ }^{24-26}$ but it is unclear whether LRP1 deletion in a specific SMC lineage affects TAA formation. Therefore, we deleted LRP1 in either CNC- or SHFderived cells. Mice with CNC-specific deletion of LRP1 using the Wnt1 promoter to drive Cre expression were embryonically lethal between E11.5 and E12.5 (Supplemental Figure IVA). Gross appearances of fetuses were comparable between genotypes at E11.5 with no obvious vascular malformation (Supplemental Figure IVB). Since this promoter is not restricted to the aorta (Supplemental Figure V), extra-aortic LRP1 deletion may have contributed to the embryonic lethality. Next, LRP1 was deleted in SHF-derived cells using a Mef2c promoter driven Cre. In Mef2c-Cre-expressing mice, Cre activity was observed mainly in the outer media (Supplemental Figure VIA). Lrp1 delta flox fragment was observed in addition to a band of native Lrp1 (Supplemental Figure VIB-D). LRP1 protein abundance was reduced by $37 \%$ in the ascending aortic media of SHF-specific LRP1 deleted mice compared to Cre negative littermates, and LRP1 deletion was restricted in the outer media (Supplemental Figure VIE-F). Mass spectrometry-assisted proteomics also verified reduction of LRP1 peptide intensity in the ascending aorta of Mef2c-Cre expressing mice (Supplemental Figure VIG).

SHF-specific LRP1 deletion did not affect growth or development of mice. To promote TAAs, Angll was infused subcutaneously for 4 weeks. LRP1 deletion in SHF- 
derived cells augmented Angll-induced aortic dilation in the ascending aorta as demonstrated by both ultrasound and confirmed by in situ imaging (Figure 6A, B). Aortic pathology was not observed in the descending thoracic aorta (Figure 6A). SHFspecific LRP1 deletion also exacerbated Angll-induced ascending aortic rupture and elastin fragmentation (Figure 6C-E). Systolic blood pressure was not different between genotypes in response to Angll infusion (Figure 6F), demonstrating that augmented aortopathy was independent of systolic blood pressure. These data, alongside our findings in SHF-derived TGFBR2, support the premise that SHF-derived cells exert a critical role in the structural integrity and aneurysm development in the ascending aorta. 


\section{Discussion}

Our study demonstrated that: (1) Several LRP1 ligands were more abundant in aortas of Angll-infused mice than saline-infused mice, and this finding was more pronounced in the descending aorta comprising cells not derived from the SHF; (2) SHF-derived cells were susceptible to Angll-induced medial thickening in the ascending aorta; (3) SHF-derived SMCs had lower abundance of elastin mRNA compared to nSHF-derived SMCs at baseline, which was reduced further during Angll infusion; (4) SHF-specific TGFBR2 deletion led to aortic malformation during the embryonic stage; and (5) LRP1 deletion in SHF-derived cells augmented Angll-induced aortopathy in mice. These results support the importance of SHF-derived cells in maintaining the integrity of the aortic wall.

A number of studies have shown an important role for TGF- $\beta$ signaling in maintaining aortic wall integrity. ${ }^{9,28}$ Both LRP1 and TGFBR2 are related to TGF- $\beta$ signaling pathways, ${ }^{28,32}$ and genetic deletions of these molecules in pan-SMCs promotes TAA formation in mice. ${ }^{9,10,24-26,31}$ In the present study, Tgfbr2 and Lrp1 gene deletion was used as a research tool. Either TGFBR2 or LRP1 was deleted in SHFderived cells to investigate the biological effects of SHF-derived cells in the aorta. Of note, SHF-specific TGFBR2 deletion led to aortic malformation and SHF-specific LRP1 deletion recapitulated aortic phenotypes in mice with its deletion in pan-SMCs. In the ascending aorta, SHF-derived cells compose half of SMCs and selected fibroblasts. ${ }^{13}$ Thus, we concluded that SHF-derived SMCs were functionally important to maintain the structural integrity of the aorta in collaborating with other types of cells derived from SHF including fibroblasts.

The promotion of thoracic aortopathy occurred by deletion of TGFBR2 or LRP1 only in SHF-derived cells. These data are consistent with the outer layers of SMC derived cells being crucial for development of thoracic aortopathies related to TGF- $\beta$ signaling. A recent study using mice expressing a fibrillin1 mutation ( $F b n 1^{\mathrm{C} 1041 \mathrm{G} /+}$ ) reported that heterozygous deletion of Notch1 in SHF-derived cells had a trend for augmenting luminal dilatation of the aortic sinus. ${ }^{33}$ In contrast, another recent study demonstrated that Smad2 deletion in CNC-derived cells reduced dilation of the aortic sinus in a mouse model of Loeys-Dietz syndrome. ${ }^{34}$ Since there are aortic regionspecific responses to TGF- $\beta,{ }^{35}$ these two developmental origins may have divergent pathophysiological functions in different aortic regions.

Elastin fragmentation is a pathological feature of TAAs and is associated with decrease of aortic resilience. ${ }^{36,37}$ As elastic fibers are one of the major aortic components and are vital for maintaining aortic structure, ${ }^{38}$ mutations of the elastin gene causes aortic stenosis due to overgrowth of SMCs. ${ }^{36,37}$ Also, SMC-specific elastin deletion induces aortic extension and coarctation in mice. ${ }^{39}$ Therefore, decreased elastin synthesis contributes to aortopathy formation. Our scRNAseq data revealed lower abundance of elastin mRNA in SMCs and fibroblasts from SHF origin compared to $\mathrm{nSHF}$ origin at both baseline and after Angll infusion. Furthermore, TGF- $\beta$ ligands and receptors were increased consistently in SHF-derived SMCs. Since TGF- $\beta$ signaling is essential for ECM maturation, this may explain the basis for the outer medial layers derived from the SHF being susceptible to aortic pathologies. Further study is needed to investigate embryonic origin-specific role of ECM-related molecules including elastin. 
Our proteomic analysis identified multiple proteins as potential targets, including several LRP ligands: plasminogen activator inhibitor 1, thrombospondin 1, CD44, fibronectin1, and matrix metalloproteinase 2 . These molecules have been implicated in medial disruption and aneurysm formation, ${ }^{40-44}$ and LRP1 removes these molecules from ECM by endocytosis. ${ }^{32}$ The proteomic analysis also identified several ribosomal proteins, Rps4x, Rps13, and Rps14. Sec61a1 and Rpn2 are associated with ribosome binding. Importantly, alteration of ribosome biogenesis has been reported in aortic dissections. ${ }^{45}$ Since these LRP1-related and ribosomal proteins were highly abundant in Angll-infused descending aorta that is a resistant region for TAAs in this model, these molecules may be protective for aortopathies. It would be interesting to investigate the role of these molecules in SHF-derived cells in development of thoracic aortopathies. In addition to proteomics, scRNAseq also detected multiple molecules including ECMrelated genes and Atn1. Interestingly, Atn1 is a unique gene detected only in nSHFderived cells at baseline. Although Atn1 is a transcriptional corepressor and contributes to SMC migration and orientation, ${ }^{46}$ the role of Atn1 in aortopathies has not been studied. Therefore, Atn1 is also an interesting target to investigate the mechanism of aortopathies.

In the present study, LRP1 deletion in CNC-derived cells did not lead to vascular malformation during the prenatal phase, but this manipulation led to embryonic lethality. Previous studies have reported that prenatal deletion of Tgfbr2 in CNC-derived cells results in cleft palate and a congenital heart defect, persistent truncus arteriosus. ${ }^{47,48}$ These mice die in the immediate perinatal period. Therefore, postnatal effects of LRP1 and TGFBR2 in CNC-specific cells on aortic integrity are unknown. However, it is not feasible to manipulate genes postnatally only in CNC-derived cells driven by Wnt 1. Since Wnt 1 is expressed in multiple tissues regardless of their embryonic origins at the postnatal phase, Wnt1-Cre will delete genes in cell types beyond CNC-derived cells. Although there is compelling evidence that CNC-derived cells exert a pivotal role in the integrity of the cardiovascular system, ${ }^{47,48}$ these data do not negate the importance of SHF-derived cells in maintaining aortic integrity. In the present study, scRNAseq data revealed the important role of SHF-derived cells on regulation of elastin and TGF- $\beta$ signaling genes. Furthermore, our mouse studies have demonstrated vascular phenotypes by gene manipulation in SHF-derived cells. These results support that SHFderived cells are crucial in maintaining aortic wall integrity. Despite this compelling evidence shows the importance of SHF-derived cells, it would be desirable to compare the postnatal role of two different SMC origins on formation of thoracic aortopathies, side by side. Development of research methods are needed to overcome the barrier to postnatal gene manipulation in each embryonic origin.

In conclusion, our study highlights the functional importance of SHF-derived cells in maintaining the integrity of the ascending aortic wall using multiple TAA mouse models. This study provides strong evidence that SHF-derived cells exert a protective role during the development of thoracic aortopathies. Heterogeneity of SMC origins contributes to complex mechanisms of aortopathy formation, which should be taken into consideration when investigating the pathophysiology of thoracic aortopathies. 


\section{Acknowledgment}

Study design: HS, HH, CZ, YL, SM, SAS, JZC, DLR, HSL, YHS, MA, MWM, AD

Implementation of animal experiments: HS, CZ, JJM, DAH, DLR

Histological analyses: HS, MKF, DAH, DLR

Data analyses: HS, YK, DLR, HSL, AD

Proteomics and associated informatics: HS, YK, HH, SM, LHL, SAS

scRNAseq and associated informatics: HS, YK, CZ, YL, YHS

Supervising and data verification: SAS, HSL, YHS, SAL, MA, MWM, AD

Writing the draft manuscript: HS

Editing the manuscript: all authors

\section{Sources of Funding}

The authors' research work was supported by the National Heart, Lung, and Blood Institute of the National Institutes of Health [R01HL133723 (AD), R01HL126901 (MA), R01HL149302 (MA), R01HL121877 (MWM)] and the American Heart Association SFRN in Vascular Disease (18SFRN33960163 and 33960114). HS was supported by an AHA postdoctoral fellowship (18POST33990468). JZC was supported by NCATS

UL1TR001998 and NHLBI F30HL143943. SAL is supported in part by the Jimmy and Roberta Howell Professorship in Cardiovascular Surgery at Baylor College of Medicine. The content in this manuscript is solely the responsibility of the authors and does not necessarily represent the official views of the National Institutes of Health.

\section{Disclosures}

The following authors have declared that no conflict of interest exists: HS, CZ, YL, YK, SM, LHL, SAS, JZC, MKF, JJM, DAH, DLR, HSL, YHS, SAL, MA, MWM, AD. HH is an employee of Kowa Company, Ltd. (Nagoya, Japan) and was a visiting scientist at Brigham and Women's Hospital when the study was conducted.

\section{Supplemental Materials \\ Supplemental Methods \\ Supplemental Table I - V \\ Supplemental Figure I - VI \\ Supplemental Excel File I - IV}




\section{Figure legends}

Figure 1. Angll differentially altered the protein profile of ascending and descending aortas of LRP1 ligands. (A) Principal component analysis of the unfiltered proteome. PC1/PC2 indicate first/second principal components; Asc, ascending aorta; and Dsc, descending aorta ( $n=3$ to 4 per group). Volcano plots for differentiated proteins between saline vs Angll in (B) ascending aorta and (C) descending aorta, and (D) ascending vs descending aortas in Angll-infused mice. (E) A Venn diagram shows the number of differentiated proteins in each comparison. (F) Heat map with Z score coloring for overlapped 41 proteins. (G) Top 3 annotations of an enrichment analysis in biological process using upregulated proteins. $(\mathbf{H})$ Fold change $\left(\log _{2}\right.$ Angll/Saline) of protein abundances related extracellular matrix (ECM) organization. (J) Western blots for Serpine1, Thbs1, and CD44 in saline or Angllinfused ascending and descending aortas ( $n=4$ to 5 per group). ${ }^{*} P<0.05,{ }^{* *} P<0.01$, ${ }^{* *} \mathrm{P}<0.001$.

Figure 2. Angll-induced medial disruption was predominantly in outer medial layers derived from the SHF. (A) Representative images of X-gal stained aortas from Wnt1- and Mef2c-Cre ROSA26R ${ }^{\text {LacZ }}$ mice ( $n=3$ per group). IA indicates innominate artery; LCA, left common carotid artery; and LSA, left subclavian artery. (B) Representative X-gal staining and FITC (fluorescein isothiocyanate) images of aortas from either saline- or Angll-infused Wnt1- and Mef2c-Cre ROSA26R ${ }^{\text {LacZ }}$ mice $(n=5$ to 7 per group). Yellow square brackets indicate medial thickening. Scale bar, $50 \mu \mathrm{m}$. Dot plots for (C) medial area and (D) X-gal positive area in the media. ${ }^{*} \mathrm{P}<0.05,{ }^{*} \mathrm{P}<0.001$ by two-way ANOVA followed by Holm-Sidak test.

Figure 3. Transmural gradients of aortic pathologies in patients with sporadic thoracic aortic aneurysms. Representative images of (A) immunostaining for $\alpha$ smooth muscle actin and (B) Movat's pentachrome staining. High magnification images are captured from the inner (blue box) and outer (red box) media. I indicates intima; M, media; $A$, adventitia. ${ }^{*} \mathrm{P}<0.01$ by Mann-Whitney $U$ test.

Figure 4. SHF-derived SMCs exhibited differential mRNA abundance related to extracellular matrix components and TGF- $\beta$ ligands and receptors. (A) Representative cross-sectional image of the aorta from Mef2c-Cre $+/ 0$ ROSA26R $\mathrm{R}^{\mathrm{mT} / \mathrm{mG}}$ mice. (B) UMAP plot of aortic cells in scRNAseq using Mef2c-Cre ROSA26R ${ }^{m T / m G}$ mice at baseline and after 3 days of Angll infusion $(n=5,4)$. Colors denote mGFP (derived from the SHF) and mTomato (not derived from the SHF, nSHF) positive cells. (C) Renamed UMAP plot including six cell types: SMC, fibroblast, Sca1+ fibroblast, endothelial cell, macrophage, and neural cell. (D) The composition of each cell type. (E) Scatter plot of differentially expressed genes in the SMC cluster at baseline and after Angll infusion. Fold change (SHF/nSHF) of genes related to (F) SMC contractility, and $(G)$ collagen, elastin, and TGF- $\beta$ ligands and receptors. NS indicates not significant.

Figure 5. TGF- $\beta$ receptor 2 deletion in SHF-derived cells provoked embryonic lethality and thoracic aortopathy at the embryonic stage. (A) Representative images of gross appearance and outflow tract of wild type littermates (left), dead 
(middle), and survived (right) fetuses with SHF-specific TGFBR2 deletion at E12.5. Blue dotted lines indicate the edge of the outflow tract. (B) Outflow diameter was measured at 300 to $400 \mu \mathrm{m}$ distal to the root of fetuses that survived at the termination. $n=5$ to 7 per group. Yellow triangles indicate retroperitoneal hemorrhage. Scale bar, $1 \mathrm{~mm}$. ${ }^{*} \mathrm{P}<0.001$ by two-tailed Student's t-test.

Figure 6. LRP1 deletion in SHF-derived cells augmented Angll-induced TAA formation and aortic rupture. (A) Representative ultrasound (US) images and in situ gross appearances of proximal thoracic aortas ( $n=21$ to 40 per group). Asc indicates ascending aorta; IA, innominate artery; and PA, pulmonary artery. Scale bar, $1 \mathrm{~mm}$. (B) Ascending aortic diameter measured by ultrasonography. (C) Cumulative probability of ascending aortic rupture. (D) Representative Movat's and Verhoeff iron hematoxylin staining. Scale bar, $50 \mu \mathrm{m}$. (E) Elastin break counts in Movat's stained sections. (F) Systolic blood pressure. ${ }^{*} \mathrm{P}<0.01$ by Log rank test, ${ }^{*} \mathrm{P}<0.001$ by two-way ANOVA followed by Holm-Sidak test. 


\section{References}

1. Goldfinger JZ, Halperin JL, Marin ML, Stewart AS, Eagle KA and Fuster V. Thoracic aortic aneurysm and dissection. J Am Coll Cardiol. 2014;64:1725-1739.

2. Hiratzka LF, Bakris GL, Beckman JA, Bersin RM, Carr VF, Casey DE, Jr., Eagle KA, Hermann LK, Isselbacher EM, Kazerooni EA, et al. 2010

ACCF/AHA/AATS/ACR/ASA/SCA/SCAI/SIR/STS/SVM Guidelines for the diagnosis and management of patients with thoracic aortic disease. A Report of the American College of Cardiology Foundation/American Heart Association Task Force on Practice Guidelines, American Association for Thoracic Surgery, American College of Radiology,American Stroke Association, Society of Cardiovascular Anesthesiologists, Society for Cardiovascular Angiography and Interventions, Society of Interventional Radiology, Society of Thoracic Surgeons, and Society for Vascular Medicine. J Am Coll Cardiol. 2010;55:e27-e129.

3. Isselbacher EM. Thoracic and abdominal aortic aneurysms. Circulation. 2005;111:816-828.

4. Albornoz G, Coady MA, Roberts M, Davies RR, Tranquilli M, Rizzo JA and Elefteriades JA. Familial thoracic aortic aneurysms and dissections--incidence, modes of inheritance, and phenotypic patterns. Ann Thorac Surg. 2006;82:14001405.

5. Trachet B, Piersigilli A, Fraga-Silva RA, Aslanidou L, Sordet-Dessimoz J, Astolfo A, Stampanoni MF, Segers $P$ and Stergiopulos N. Ascending aortic aneurysm in angiotensin II-infused mice: Formation, progression, and the role of focal dissections. Arterioscler Thromb Vasc Biol. 2016;36:673-681.

6. Daugherty A, Rateri DL, Charo IF, Owens AP, Howatt DA and Cassis LA. Angiotensin II infusion promotes ascending aortic aneurysms: attenuation by CCR2 deficiency in apoE-/- mice. Clin Sci (Lond). 2010;118:681-689.

7. Wanga S, Hibender S, Ridwan Y, van Roomen C, Vos M, van der Made I, van Vliet N, Franken R, van Riel LA, Groenink M, et al. Aortic microcalcification is associated with elastin fragmentation in Marfan syndrome. J Pathol. 2017;243:294-306.

8. Sawada H, Chen JZ, Wright BC, Sheppard MB, Lu HS and Daugherty A. Heterogeneity of aortic smooth muscle cells: A determinant for regional characteristics of thoracic aortic aneurysms? J Transl Int Med. 2018;6:93-96.

9. Li W, Li Q, Jiao Y, Qin L, Ali R, Zhou J, Ferruzzi J, Kim RW, Geirsson A, Dietz HC, et al. Tgfbr2 disruption in postnatal smooth muscle impairs aortic wall homeostasis. J Clin Invest. 2014;124:755-767.

10. Yang P, Schmit BM, Fu C, DeSart K, Oh SP, Berceli SA and Jiang Z. Smooth muscle cell-specific Tgfbr1 deficiency promotes aortic aneurysm formation by stimulating multiple signaling events. Sci Rep. 2016;6:35444.

11. Quintana RA and Taylor WR. Cellular mechanisms of aortic aneurysm formation. Circ Res. 2019;124:607-618.

12. Majesky MW. Developmental basis of vascular smooth muscle diversity. Arterioscler Thromb Vasc Biol. 2007;27:1248-1258.

13. Sawada H, Rateri DL, Moorleghen JJ, Majesky MW and Daugherty A. Smooth muscle cells derived from second heart field and cardiac neural crest reside in spatially distinct domains in the media of the ascending aorta-Brief report.

Arterioscler Thromb Vasc Biol. 2017;37:1722-1726. 
14. Rateri DL, Davis FM, Balakrishnan A, Howatt DA, Moorleghen JJ, O'Connor WN, Charnigo R, Cassis LA and Daugherty A. Angiotensin II induces region-specific medial disruption during evolution of ascending aortic aneurysms. Am J Pathol. 2014;184:2586-2595.

15. Owens AP, 3rd, Subramanian V, Moorleghen JJ, Guo Z, McNamara CA, Cassis LA and Daugherty A. Angiotensin II induces a region-specific hyperplasia of the ascending aorta through regulation of inhibitor of differentiation 3. Circ Res. 2010;106:611-619.

16. Robinet P, Milewicz DM, Cassis LA, Leeper NJ, Lu HS and Smith JD. Consideration of sex differences in design and reporting of experimental arterial pathology studies-statement from ATVB council. Arterioscler Thromb Vasc Biol. 2018;38:292-303.

17. Lu H, Howatt DA, Balakrishnan A, Moorleghen JJ, Rateri DL, Cassis LA and Daugherty A. Subcutaneous angiotensin II infusion using osmotic pumps induces aortic aneurysms in mice. J Vis Exp. 2015:10.3791/53191.

18. Luo W, Wang Y, Zhang L, Ren P, Zhang C, Li Y, Azares AR, Zhang M, Guo J, Ghaghada KB, et al. Critical Role of Cytosolic DNA and Its Sensing Adaptor STING in Aortic Degeneration, Dissection, and Rupture. Circulation. 2020;141:42-66.

19. Szklarczyk D, Gable AL, Lyon D, Junge A, Wyder S, Huerta-Cepas J, Simonovic M, Doncheva NT, Morris JH, Bork P, et al. STRING v11: protein-protein association networks with increased coverage, supporting functional discovery in genome-wide experimental datasets. Nucleic Acids Res. 2019;47:D607-D613.

20. Chen EY, Tan CM, Kou Y, Duan Q, Wang Z, Meirelles GV, Clark NR and Ma'ayan A. Enrichr: interactive and collaborative HTML5 gene list enrichment analysis tool. BMC Bioinformatics. 2013;14:128.

21. Butler A, Hoffman $P$, Smibert $P$, Papalexi E and Satija R. Integrating single-cell transcriptomic data across different conditions, technologies, and species. Nat Biotechnol. 2018;36:411-420.

22. Risso D, Perraudeau F, Gribkova S, Dudoit S and Vert JP. A general and flexible method for signal extraction from single-cell RNA-seq data. Nat Commun. 2018;9:284.

23. Robinson MD, McCarthy DJ and Smyth GK. edgeR: a Bioconductor package for differential expression analysis of digital gene expression data. Bioinformatics. 2010;26:139-140.

24. Boucher P, Gotthardt M, Li WP, Anderson RG and Herz J. LRP: role in vascular wall integrity and protection from atherosclerosis. Science. 2003;300:329-332.

25. Davis FM, Rateri DL, Balakrishnan A, Howatt DA, Strickland DK, Muratoglu SC, Haggerty CM, Fornwalt BK, Cassis LA and Daugherty A. Smooth muscle cell deletion of low-density lipoprotein receptor-related protein 1 augments angiotensin Il-induced superior mesenteric arterial and ascending aortic aneurysms. Arterioscler Thromb Vasc Biol. 2015;35:155-162.

26. Basford JE, Koch S, Anjak A, Singh VP, Krause EG, Robbins N, Weintraub NL, Hui DY and Rubinstein J. Smooth muscle LDL receptor-related protein-1 deletion induces aortic insufficiency and promotes vascular cardiomyopathy in mice. PLoS One. 2013;8:e82026. 
27. Muratoglu SC, Belgrave S, Hampton B, Migliorini M, Coksaygan T, Chen L, Mikhailenko I and Strickland DK. LRP1 protects the vasculature by regulating levels of connective tissue growth factor and HtrA1. Arterioscler Thromb Vasc Biol. 2013;33:2137-2146.

28. Lindsay ME and Dietz HC. Lessons on the pathogenesis of aneurysm from heritable conditions. Nature. 2011;473:308-316.

29. Schmit BM, Yang P, Fu C, DeSart K, Berceli SA and Jiang Z. Hypertension overrides the protective effect of female hormones on the development of aortic aneurysm secondary to Alk5 deficiency via ERK activation. Am J Physiol Heart Circ Physiol. 2015;308:H115-125.

30. Gallo EM, Loch DC, Habashi JP, Calderon JF, Chen Y, Bedja D, van Erp C, Gerber EE, Parker SJ, Sauls K, et al. Angiotensin II-dependent TGF-beta signaling contributes to Loeys-Dietz syndrome vascular pathogenesis. J Clin Invest. 2014;124:448-460.

31. Hu JH, Wei H, Jaffe M, Airhart N, Du L, Angelov SN, Yan J, Allen JK, Kang I, Wight $\mathrm{TN}$, et al. Postnatal deletion of the type II transforming growth factor-beta receptor in smooth muscle cells causes severe aortopathy in mice. Arterioscler Thromb Vasc Biol. 2015;35:2647-2656.

32. Strickland DK, Au DT, Cunfer P and Muratoglu SC. Low-density lipoprotein receptor-related protein-1: role in the regulation of vascular integrity. Arterioscler Thromb Vasc Biol. 2014;34:487-498.

33. Koenig SN, LaHaye S, Feller JD, Rowland P, Hor KN, Trask AJ, Janssen PM, Radtke F, Lilly B and Garg V. Notch1 haploinsufficiency causes ascending aortic aneurysms in mice. JCl Insight. 2017;2:10.1172/jci.insight.91353.

34. MacFarlane EG, Parker SJ, Shin JY, Kang BE, Ziegler SG, Creamer TJ, Bagirzadeh R, Bedja D, Chen Y, Calderon JF, et al. Lineage-specific events underlie aortic root aneurysm pathogenesis in Loeys-Dietz syndrome. J Clin Invest. 2019;129:659-675.

35. Topouzis S and Majesky MW. Smooth muscle lineage diversity in the chick embryo. Two types of aortic smooth muscle cell differ in growth and receptor-mediated transcriptional responses to transforming growth factor-beta. Dev Biol. 1996;178:430-445.

36. Li DY, Brooke B, Davis EC, Mecham RP, Sorensen LK, Boak BB, Eichwald E and Keating MT. Elastin is an essential determinant of arterial morphogenesis. Nature. 1998;393:276-280.

37. Curran ME, Atkinson DL, Ewart AK, Morris CA, Leppert MF and Keating MT. The elastin gene is disrupted by a translocation associated with supravalvular aortic stenosis. Cell. 1993;73:159-168.

38. Shen YH and LeMaire SA. Molecular pathogenesis of genetic and sporadic aortic aneurysms and dissections. Curr Probl Surg. 2017;54:95-155.

39. Lin CJ, Staiculescu MC, Hawes JZ, Cocciolone AJ, Hunkins BM, Roth RA, Lin CY, Mecham RP and Wagenseil JE. Heterogeneous cellular contributions to elastic laminae formation in arterial wall development. Circ Res. 2019;125:1006-1018.

40. Allaire E, Hasenstab D, Kenagy RD, Starcher B, Clowes MM and Clowes AW. Prevention of aneurysm development and rupture by local overexpression of plasminogen activator inhibitor-1. Circulation. 1998;98:249-255. 
41. Yamashiro Y, Thang BQ, Shin SJ, Lino CA, Nakamura T, Kim J, Sugiyama K, Tokunaga $\mathrm{C}$, Sakamoto $\mathrm{H}$, Osaka $\mathrm{M}$, et al. Role of thrombospondin-1 in mechanotransduction and development of thoracic aortic aneurysm in mouse and humans. Circ Res. 2018;123:660-672.

42. Shen M, Lee J, Basu R, Sakamuri SS, Wang X, Fan D and Kassiri Z. Divergent roles of matrix metalloproteinase 2 in pathogenesis of thoracic aortic aneurysm. Arterioscler Thromb Vasc Biol. 2015;35:888-898.

43. Paloschi V, Kurtovic S, Folkersen L, Gomez D, Wagsater D, Roy J, Petrini J, Eriksson MJ, Caidahl K, Hamsten A, et al. Impaired splicing of fibronectin is associated with thoracic aortic aneurysm formation in patients with bicuspid aortic valve. Arterioscler Thromb Vasc Biol. 2011;31:691-697.

44. Hatipoglu OF, Miyoshi T, Yonezawa T, Kondo M, Amioka N, Yoshida M, Akagi S, Nakamura K, Hirohata S and Ito H. Deficiency of CD44 prevents thoracic aortic dissection in a murine model. Sci Rep. 2020;10:6869.

45. Wu Q, Hong J, Wang Z, Hu J, Chen R, Hu Z, Li B, Hu X, Zhang Z and Ruan Y. Abnormal ribosome biogenesis partly induced p53-dependent aortic medial smooth muscle cell apoptosis and oxidative stress. Oxid Med Cell Longev. 2019;2019:7064319.

46. Hou R and Sibinga NE. Atrophin proteins interact with the Fat1 cadherin and regulate migration and orientation in vascular smooth muscle cells. J Biol Chem. 2009;284:6955-6965.

47. Ito Y, Yeo JY, Chytil A, Han J, Bringas P, Jr., Nakajima A, Shuler CF, Moses HL and Chai $Y$. Conditional inactivation of Tgfbr2 in cranial neural crest causes cleft palate and calvaria defects. Development. 2003;130:5269-5280.

48. Choudhary B, Ito Y, Makita T, Sasaki T, Chai Y and Sucov HM. Cardiovascular malformations with normal smooth muscle differentiation in neural crest-specific type II TGFbeta receptor (Tgfbr2) mutant mice. Dev Biol. 2006;289:420-429. 
A

B Saline vs Angll C Saline vs Angll

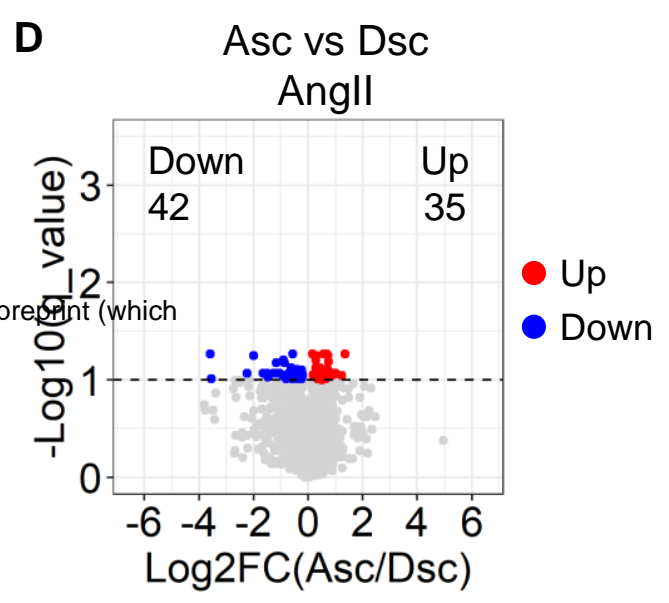

Total: 2644 proteins Angll

Saline

PC2

Asc Dsc

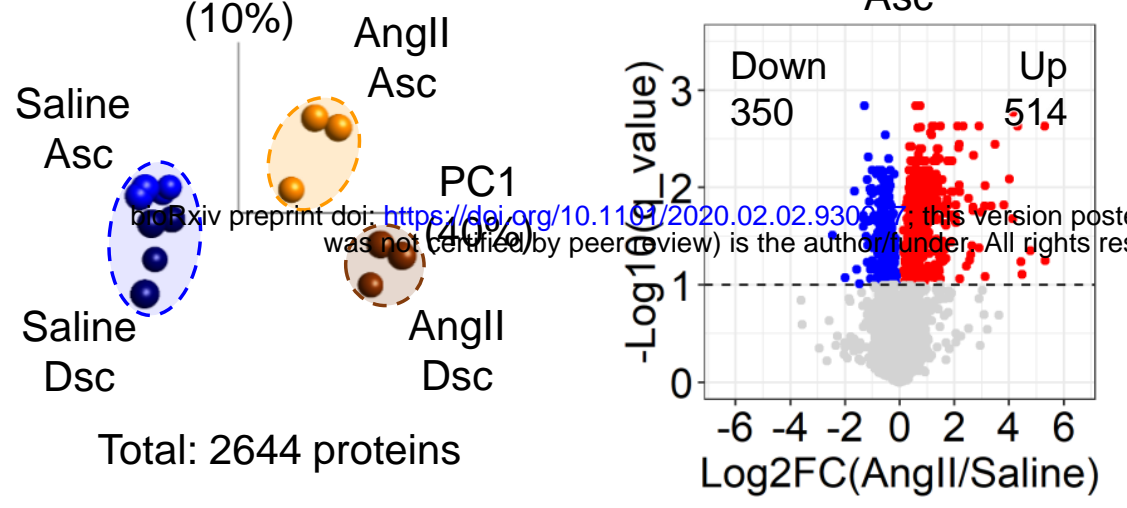

E

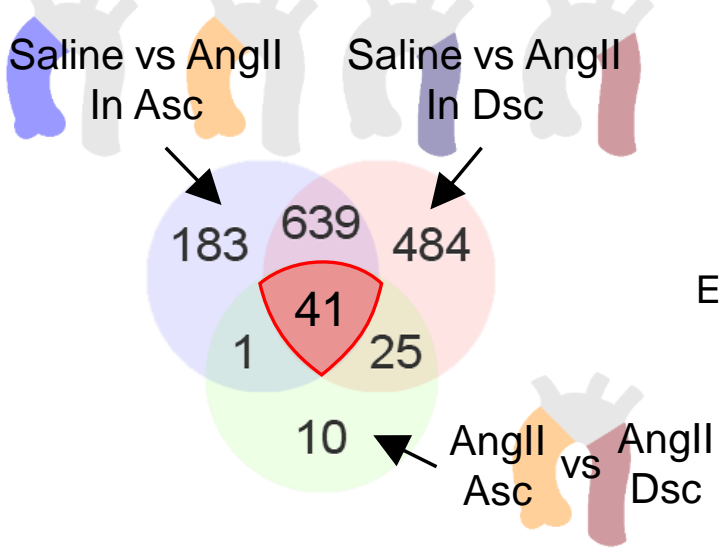

G

H

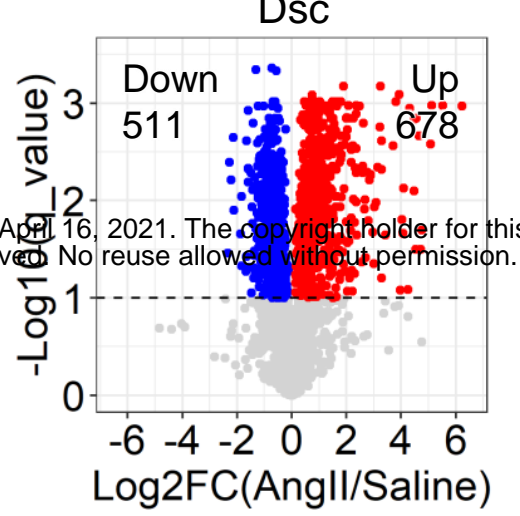

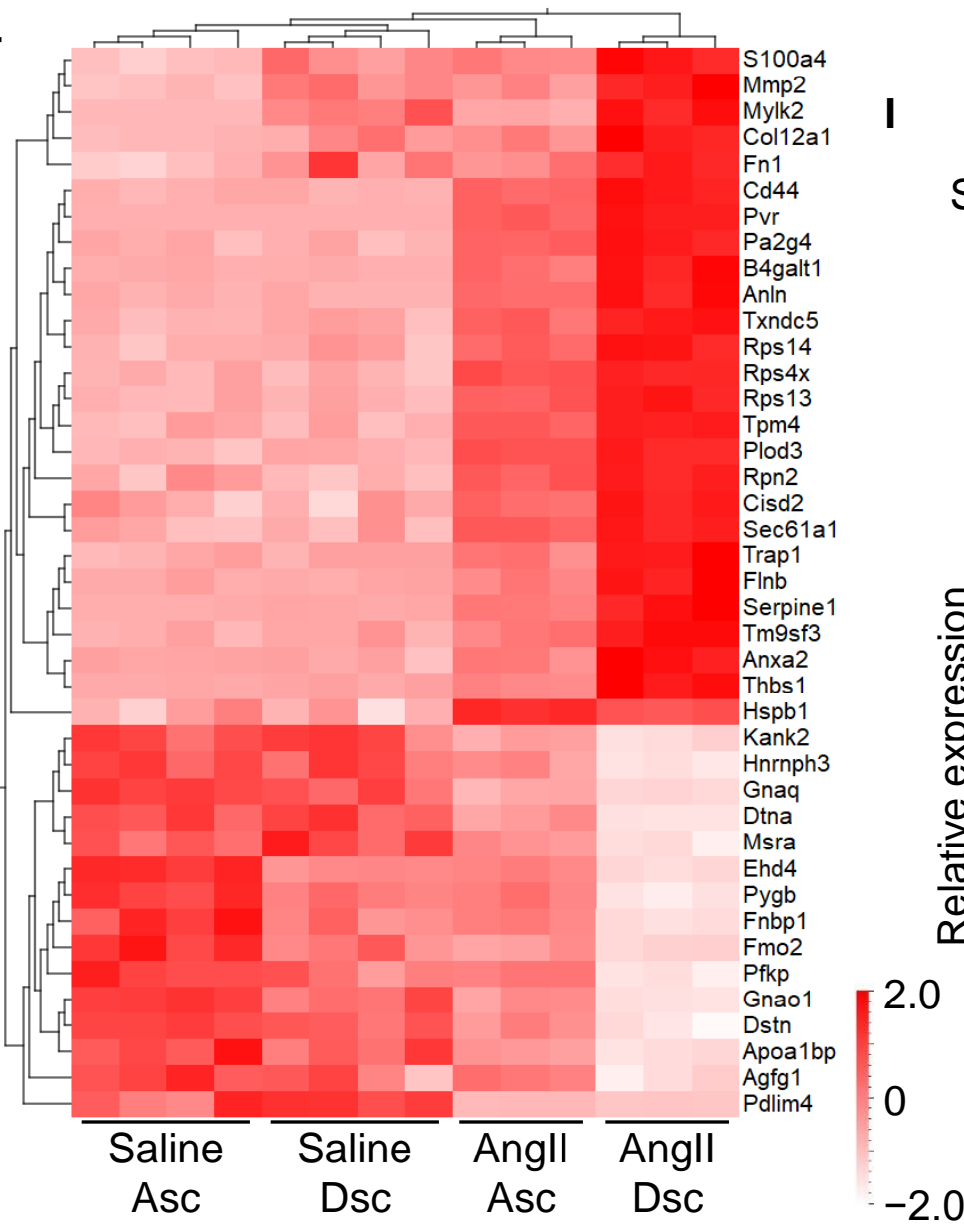

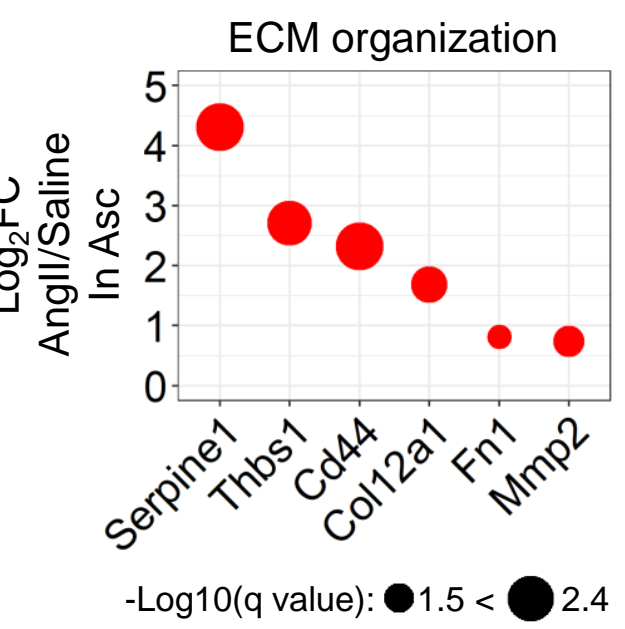

Biological Process

Protein targeting to $\mathrm{ER}$ Endodermal cell differentiation

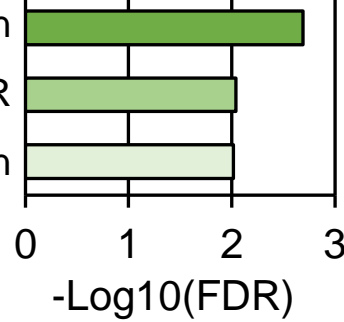

-Log10(q value):

(kDa)

Serpine1

Thbs1

Cd44

$\beta$-actin

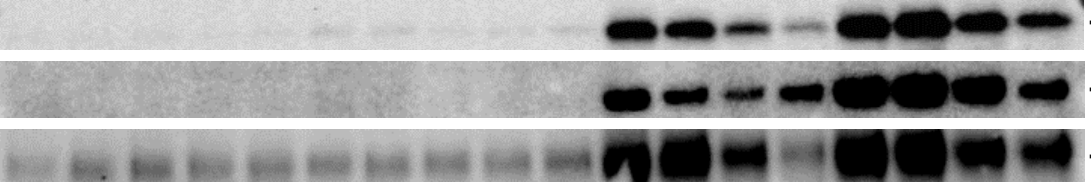

47

$-174$

82

Saline - Asc $\overline{\text { Saline - Dsc }} \overline{\text { Angll - Asc }} \overline{\text { Angll - Dsc }}$

$-42$

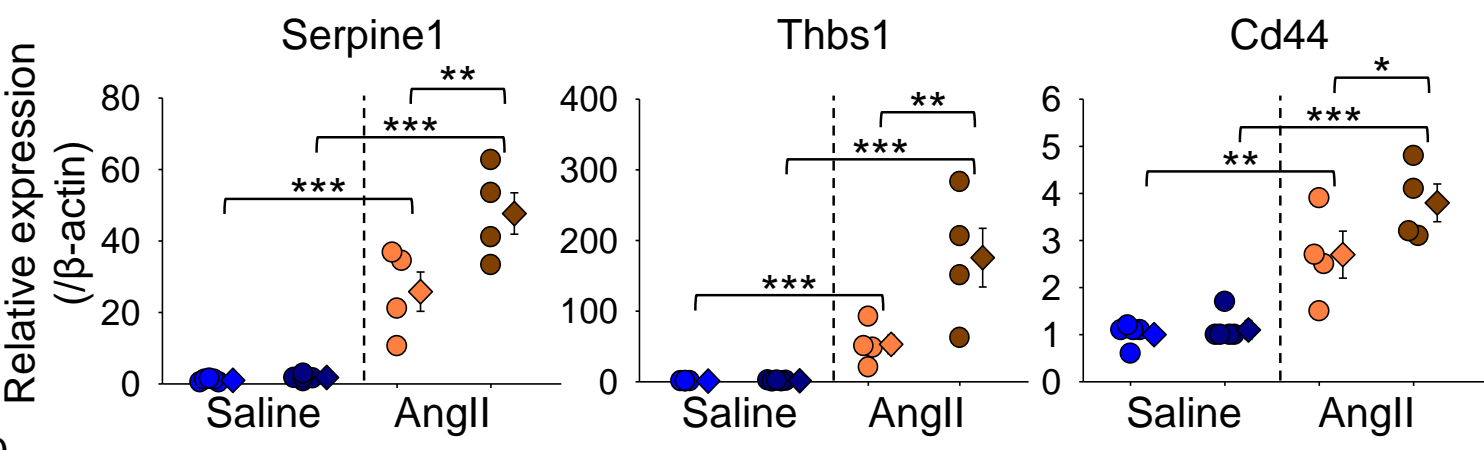

- Saline-Asc • Saline-Dsc $\odot$ Angll-Asc • Angll-Dsc

Figure 1. Angll differentially altered the protein profile of ascending and descending aortas of LRP1 ligands.

(A) Principal component analysis of the unfiltered proteome. PC1/PC2 indicate first/second principal components; Asc, ascending aorta; and Dsc, descending aorta ( $n=3$ to 4 per group). Volcano plots for differentiated proteins between saline vs Angll in (B) ascending aorta and (C) descending aorta, and (D) ascending vs descending aortas in Angllinfused mice. (E) A Venn diagram shows the number of differentiated proteins in each comparison. (F) Heat map with $Z$ score coloring for overlapped 41 proteins. (G) Top 3 annotations of an enrichment analysis in biological process using upregulated proteins. (H) Fold change ( $\mathrm{Log}_{2}$ Angll/Saline) of protein abundances related extracellular matrix(ECM) organization. (J) Western blots for Serpine1, Thbs1, and CD44 in saline or Angll-infused ascending and descending aortas ( $n=4$ to 5 per group). ${ }^{*} \mathrm{P}<0.05,{ }^{* *} \mathrm{P}<0.01,{ }^{* *} \mathrm{P}<0.001$. 
bioRxiv preprint doi: https://doi.org/10.1101/2020.02.02.930917; this version posted April 16, 2021. The copyright holder for this preprint (which was not certified by peer review) is the author/funder. All rights reserved. No reuse allowed without permission.

A
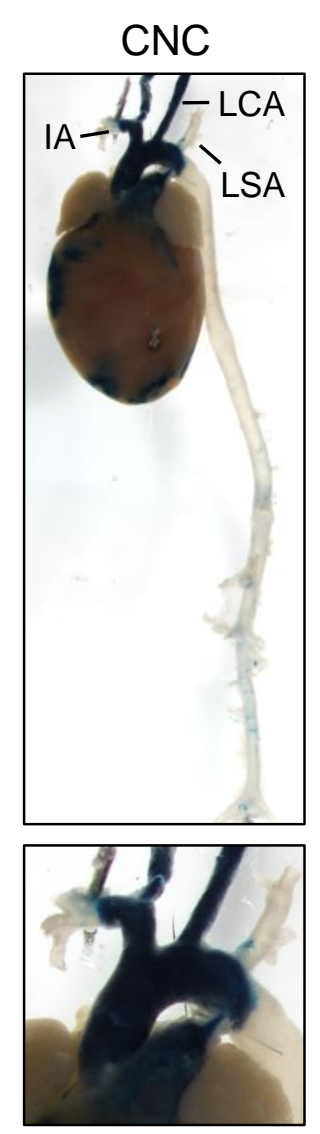

SHF
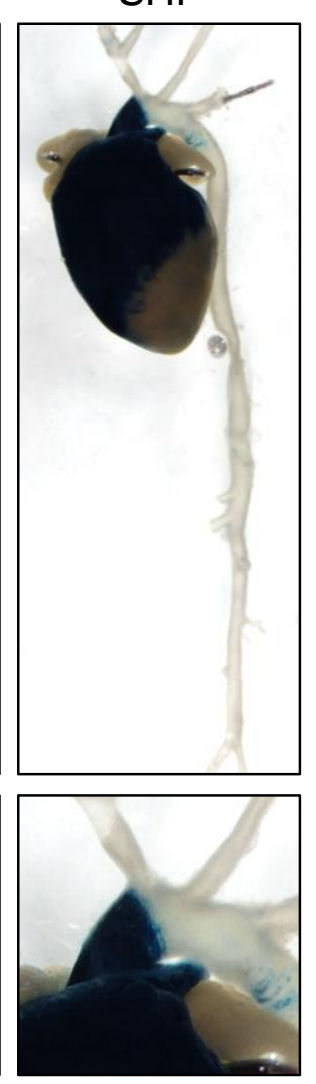

B

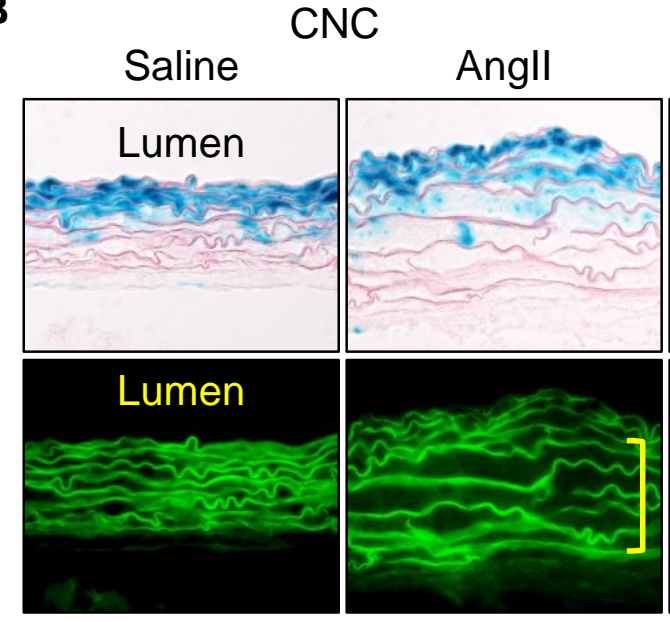

C

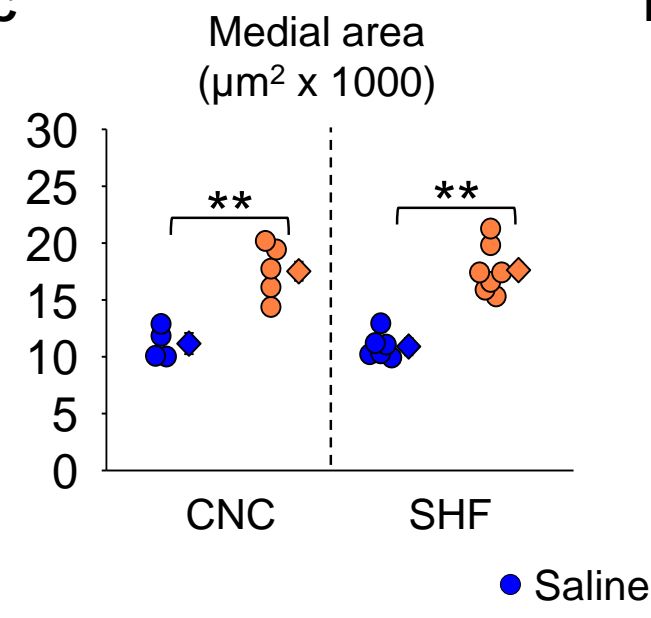

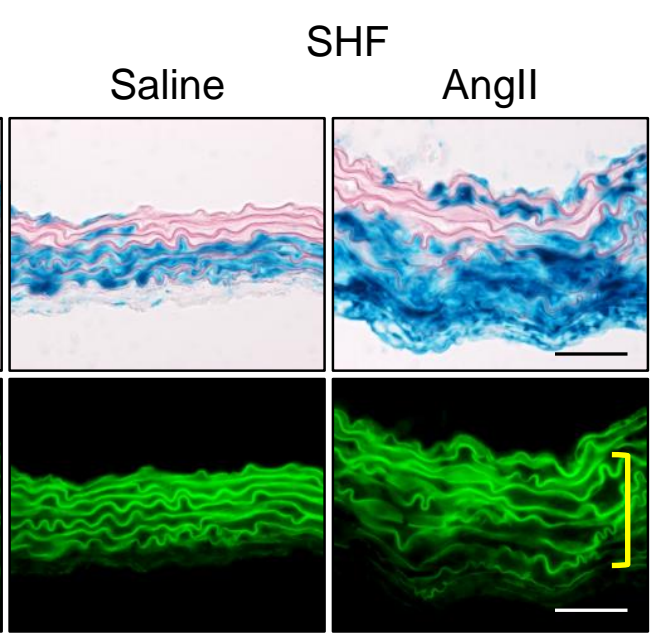

D

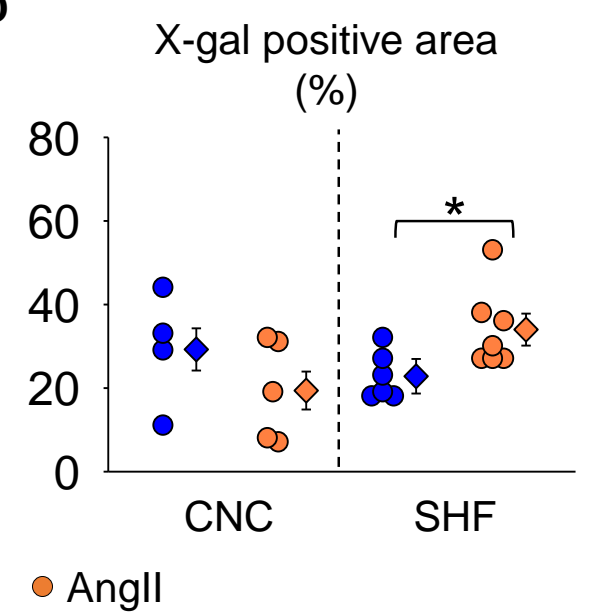

Figure 2. Angll-induced medial disruption was predominantly in outer medial layers derived from the SHF. (A) Representative images of X-gal stained aortas from Wnt1- and Mef2c-Cre ROSA26R ${ }^{\text {LacZ }}$ mice ( $n=3$ per group). IA indicates innominate artery; LCA, left common carotid artery; and LSA, left subclavian artery. (B) Representative X-gal staining and FITC (fluorescein isothiocyanate) images of aortas from either saline- or Angll-infused Wnt1and Mef2c-Cre ROSA26R ${ }^{L a c Z}$ mice ( $n=5$ to 7 per group). Yellow square brackets indicate medial thickening. Scale bar, $50 \mu \mathrm{m}$. Dot plots for (C) medial area and (D) X-gal positive area in the media. ${ }^{*} P<0.05,{ }^{* *} \mathrm{P}<0.001$ by two-way ANOVA followed by Holm-Sidak test. 
A

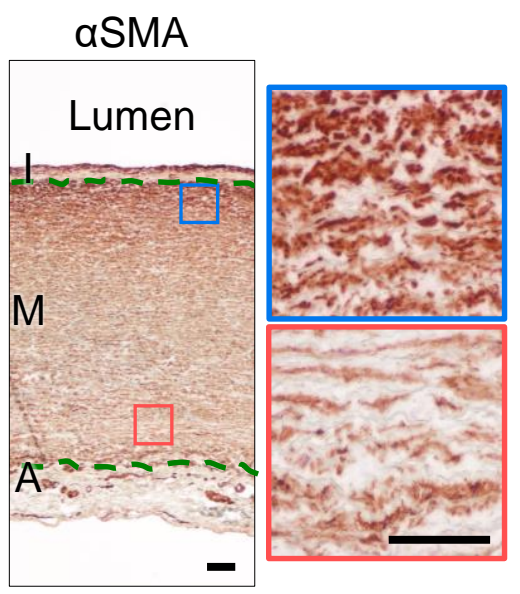

B

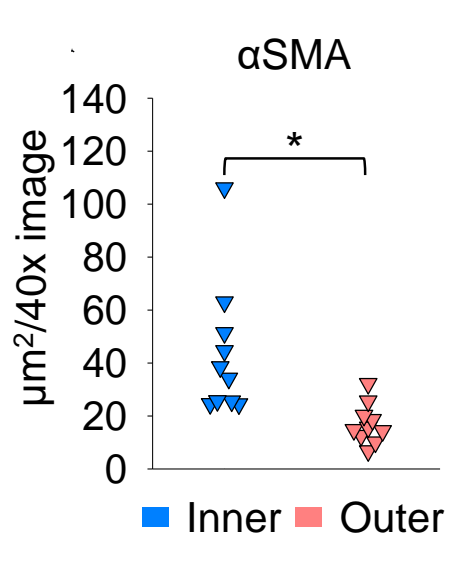

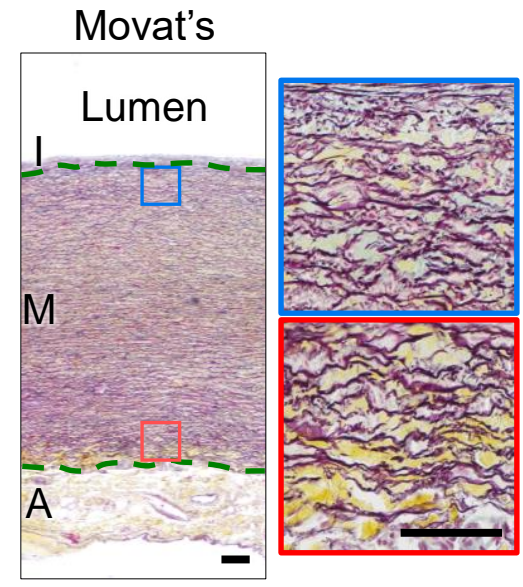

Figure 3. Transmural gradients of aortic pathologies in patients with sporadic thoracic aortic aneurysms. Representative images of (A) immunostaining for $\alpha$-smooth muscle actin and (B) Movat's pentachrome staining. High magnification images are captured from the inner (blue box) and outer (red box) media. I indicates intima; $M$, media; $A$, adventitia. ${ }^{* *} \mathrm{P}<0.01$ by Mann-Whitney $U$ test. 
A

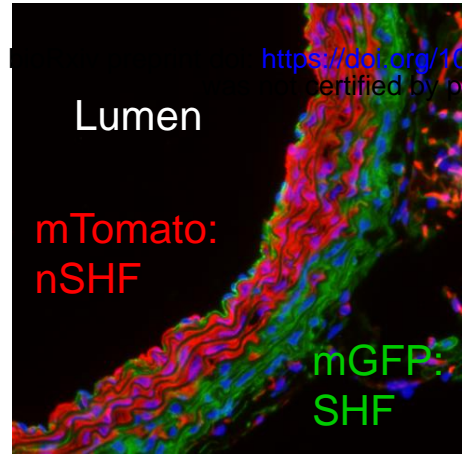

Mef2c-Cre $+/ 0$

B

Baseline

1101/2020.02.02.930917; this version posted April 16, 2021. The copyright holder for this preprint (which eer review) is the author/funder. All rights reserved.-No reuse allowed without permission.

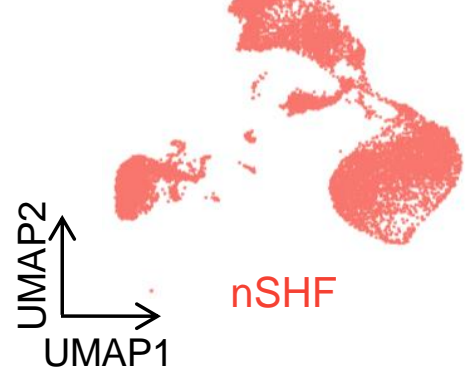

D Integrated

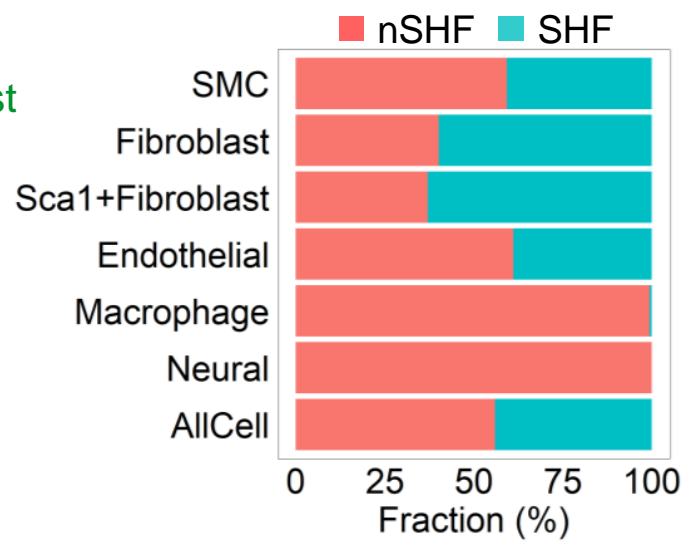

$\mathbf{E}$

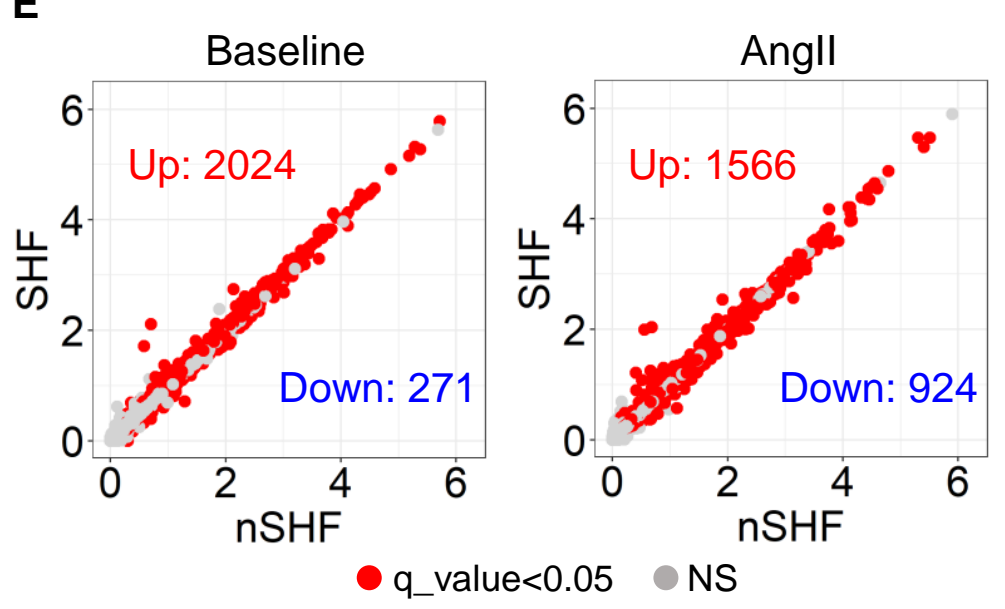

$\mathbf{F}$

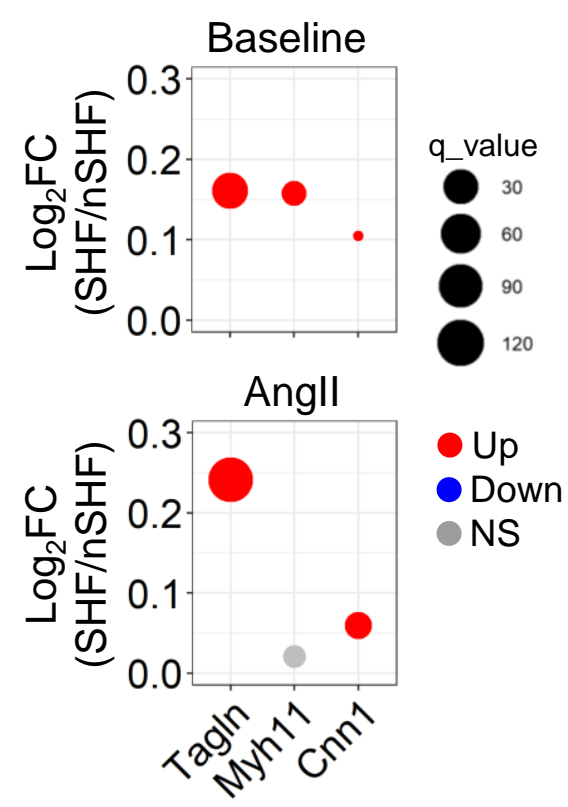

G

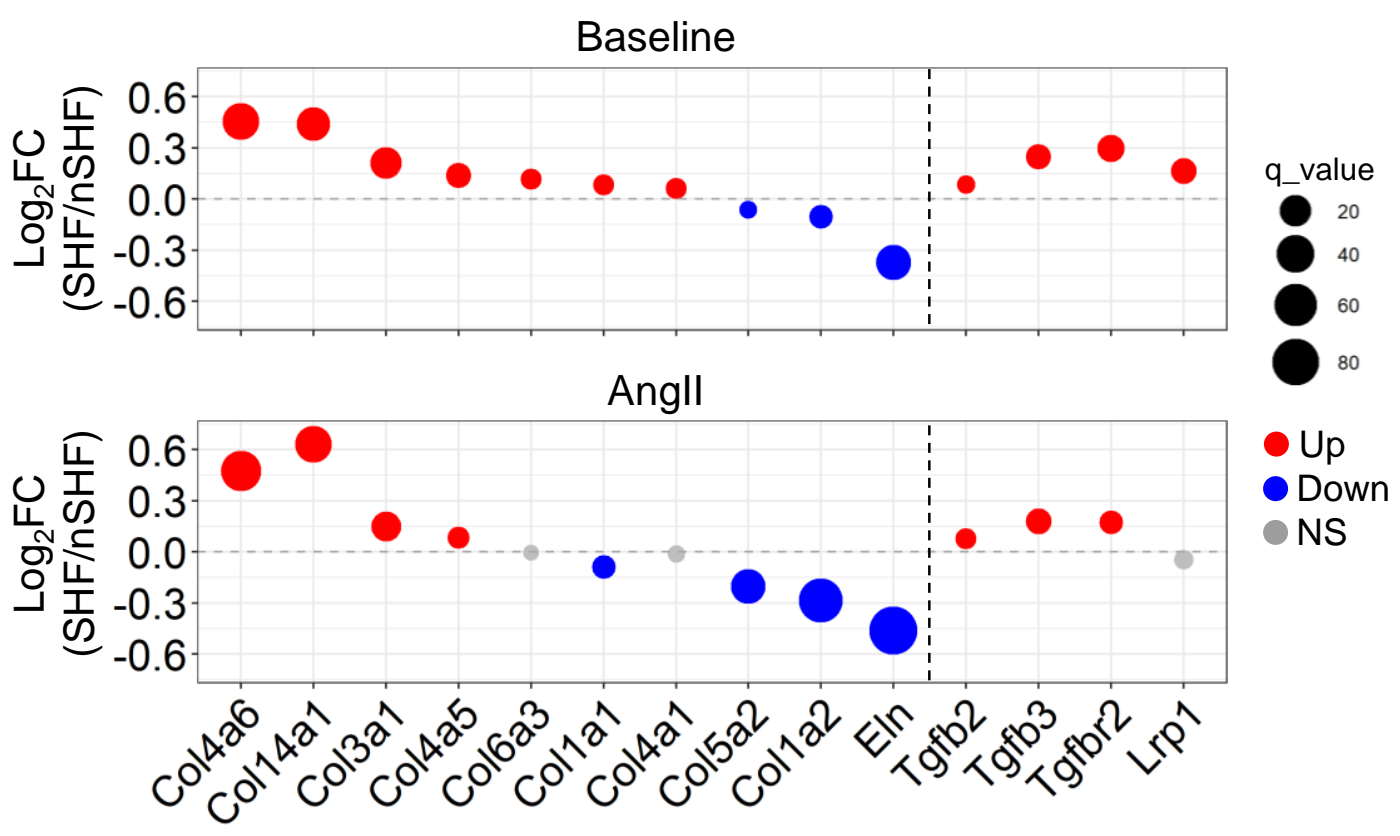

Figure 4. SHF-derived SMCs exhibited differential mRNA abundance related to extracellular matrix components and TGF- $\beta$ ligands and receptors. (A) Representative cross-sectional image of the aorta from Mef2c-Cre $+/ 0$ ROSA26R ${ }^{m T / m G}$ mice. (B) UMAP plot of aortic cells in scRNAseq using Mef2c-Cre ROSA26R ${ }^{m T / m G}$ mice at baseline and after 3 days of Angll infusion ( $n=5,4)$. Colors denote mGFP (derived from the SHF) and mTomato (not derived from the SHF, nSHF) positive cells. (C) Renamed UMAP plot including six cell types: SMC, fibroblasts, Sca1+ fibroblasts, endothelial cells, macrophages, and neural cells. (D) The composition of each cell type. (E) Scatter plot of differentially expressed genes in the SMC cluster at baseline and after Angll infusion. Fold change (SHF/nSHF) of genes related to (F) SMC contractility, and (G) collagen, elastin, and TGF- $\beta$ ligands and receptors. NS indicates not significant. 
A

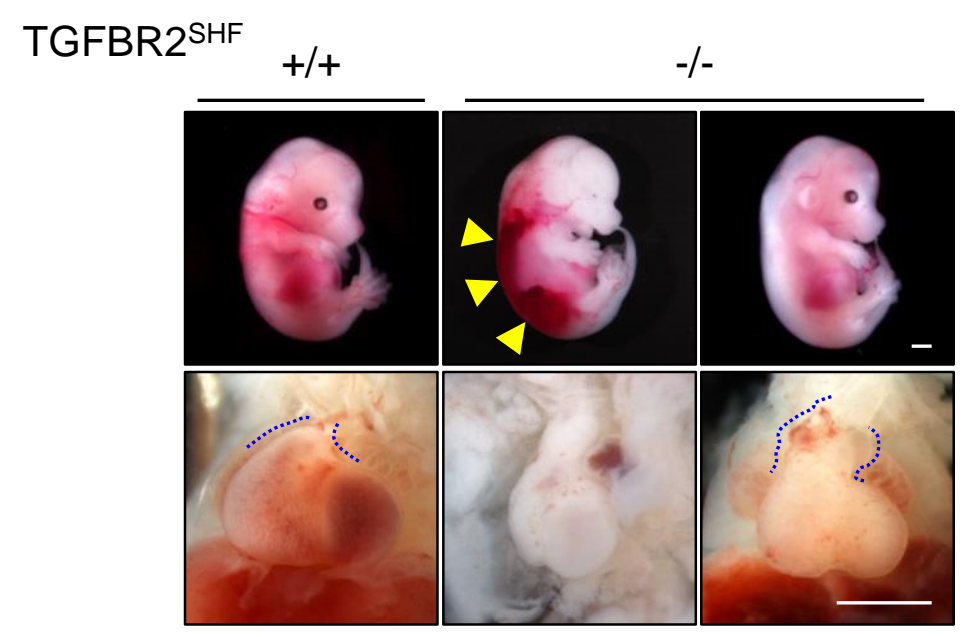

B

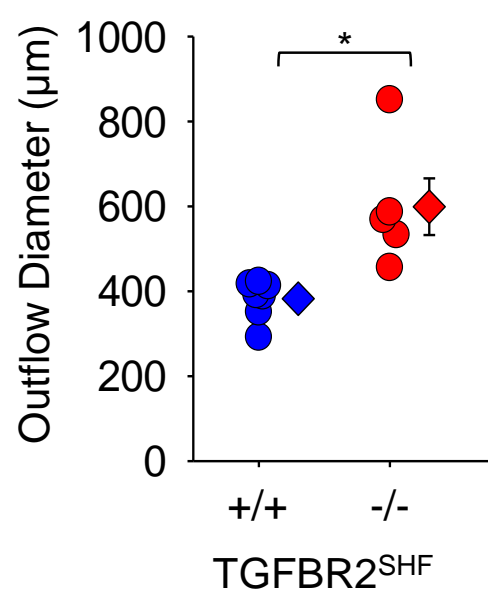

Figure 5. TGF- $\beta$ receptor 2 deletion in SHF-derived cells provoked embryonic lethality and thoracic aortopathy at the embryonic stage. (A) Representative images of gross appearance and outflow tract of wild type littermates (left), dead (middle), and survived (right) fetuses with SHF-specific TGFBR2 deletion at E12.5. Blue dotted lines indicate the edge of the outflow tract. (B) Outflow diameter was measured at 300 to $400 \mu \mathrm{m}$ distal to the root of fetuses that survived at the termination $(n=5$ to 7 per group). Yellow triangles indicate retroperitoneal hemorrhage. Scale bar, $1 \mathrm{~mm}$. ${ }^{*} \mathrm{P}<0.001$ by two-tailed Student's t-test. 
bioRxiv preprint doi: https://doi.org/10.1101/2020.02.02.930917; this version posted April 16, 2021. The copyright holder for this preprint (which was not certified by peer review) is the author/funder. All rights reserved. No reuse allowed without permission.
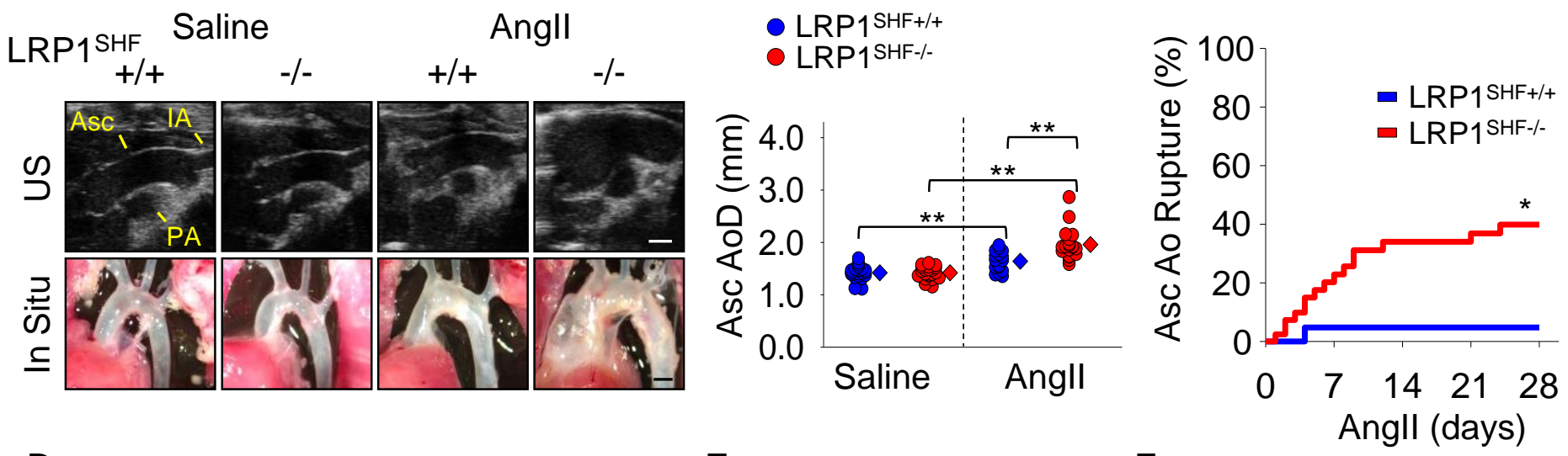

D

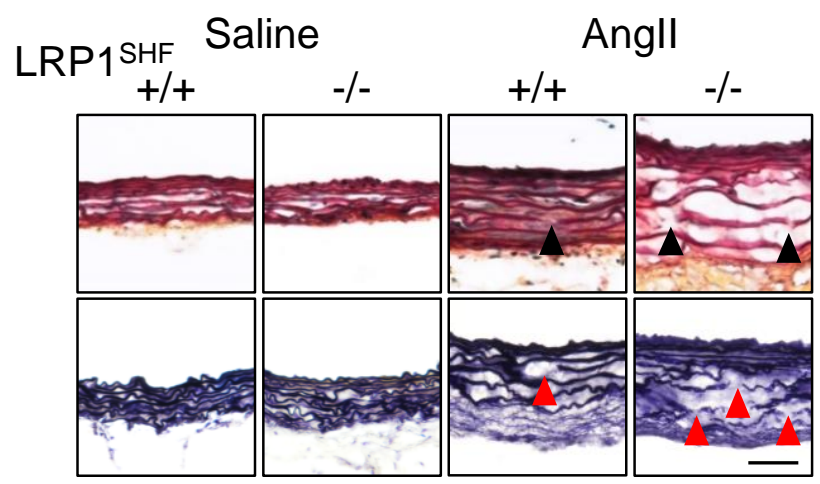

E

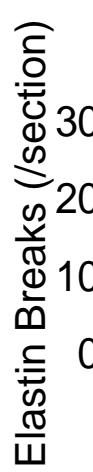

$\mathbf{F}$

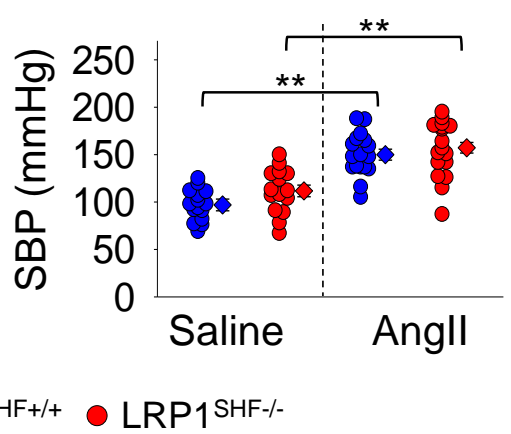

Figure 6. LRP1 deletion in SHF-derived cells augmented Angll-induced TAA formation and aortic rupture. (A) Representative ultrasound (US) images and in situ gross appearances of proximal thoracic aortas ( $\mathrm{n}=21$ to 40 per group). Asc indicates ascending aorta; IA, innominate artery; and PA, pulmonary artery. Scale bar, $1 \mathrm{~mm}$. (B) Ascending aortic diameter measured by ultrasonography. (C) Cumulative probability of ascending aortic rupture. (D) Representative Movat's and Verhoeff iron hematoxylin staining. Scale bar, $50 \mu \mathrm{m}$. (E) Elastin break counts in Movat's stained sections. (F) Systolic blood pressure. ${ }^{*} \mathrm{P}<0.01$ by Log rank test, ${ }^{* *} \mathrm{P}<0.001$ by two-way ANOVA followed by HolmSidak test. 